Jurnal Basicedu Volume 4 Nomor 2 April 2020 Hal. 344- 354

JURNAL BASICEDU

Research \& Learning in Elementary Education

https://jbasic.org/index.php/basicedu

\title{
EFEKTIVITAS MODEL PEMBELAJARAN PROJECT BASED LEARNING BERBASIS STEM DAN TIDAK BERBASIS STEM TERHADAP KETERAMPILAN BERPIKIR KRITIS SISWA
}

\author{
Almahida Aureola Dywan ${ }^{1}$, Gamaliel Septian Airlanda ${ }^{2}$ \\ Universitas Kristen Satya Wacana, Jawa Tengah, Indonesia ${ }^{1,2}$ \\ Email: Almahidad998@gmail.com¹.Gamaliel.septian@uksw.edu²
}

\begin{abstract}
Abstrak
Penelitian ini bertujuan untuk menguji keefektifan penggunaan model pembelajaran PJBL (Project Based Learning) berbasis STEM (Science, Technology, Engineering, Mathemathic) dan tidak berbasis STEM terhadap keterampilan berpikir kritis siswa kelas IV. Populasi gugus Gajah Mada kecamatan Sidomukti kota Salatiga, dengan sampel SD Negeri Dukuh 01 Salatiga sebagai kelompok eksperimen berjumlah 32 siswa dan SD Negeri Kecandran 01 Salatiga sebagai kelompok kontrol berjumlah 33 siswa. Penelitian ini yang menggunakan Quasi Eksperimental dengan desain penelitian Non-equivalen Control Group Desain untuk mengetahui keberhasilan pengujian perlu dilakukan Pre-test dan Post-test. Hasil penelitian dilihat dari uji independen T tes dengan signifikansi 0,038<0,05 menggunakan SPSS 20 for Windows yang berarti terdapat pengaruh yang signifikan sehingga $\mathrm{H}_{0}$ ditolak dan $\mathrm{H}_{1}$ diterima serta hasil rata-rata pre-test ke post-test pada kelompok eksperiemen yang meningkat sebesar 13,38 sedangkan pada kelompok kontrol meningkat sebesar 7,51.Penggunaan model pembelajaran PJBL berbasis STEM lebih efektif dalam meningkatkan keterampilan berpikir kritis siswa kelas IV muatan pembelajaran IPA.
\end{abstract}

Kata Kunci: PJBL berbasis STEM, PJBL, berpikir kritis, muatan pelajaran IPA

\begin{abstract}
The purpose of this research is to know about the effectiveness PJBL (project based learning model) based on STEM (Science, Technology, Engineering, Mathematics) and not base on STEM to critical thinking grade 4th students. Population from gugus Gajah Mada in the Sidomukti sub-district of Salatiga city, with a sample of SD Negeri Dukuh 01 Salatiga as an experimental group totaling 32 students and SD Negeri Kecandran 01 Salatiga as a control group totaling 33 students. This research used Quasi experimental with Non-aquivalent control group design to know about testing success must use pretest and posttest. The results this research can see from Independent T-Test with significance 0,038 $<0,05$ use SPSS 20 for Windows that's mean have effect significant, so $\mathrm{H}_{0}$ is rejected and $\mathrm{H}_{1}$ is accepted then the mean of pretest to posttest in experimental class increased 13,38 than control class increased 7,51. As a result, using PJBL model based on STEM more effective to increase critical thinking grade 4th students in science.
\end{abstract}

Keywords: STEM-based PJBL, PJBL, critical thinking, the content of science lessons

@ Jurnal Basicedu Prodi PGSD FIP UPTT 2020

$\triangle$ Corresponding author :

Address :-

ISSN 2580-3735 (Media Cetak)

Email : ISSN 2580-1147 (Media Online)

Phone :- 


\section{PENDAHULUAN}

Sistem pendidikan yang digunakan pada saat ini adalah kurikulum 2013 yang diharapkan mampu mengubah pendidikan menjadi lebih aktif, kreatif dan menciptakan proses berpikir kritis serta mampu mengikuti perkembangan zaman. Banyak cara yang dapat dilakukan guru untuk mengembangkan keterampilan berpikir kritis sehingga siswa mampu mengikuti perkembangan pembelajaran sesuai dengan zaman. Pembelajaran IPA menjadi hal menarik untuk dipelajari apabila dikaitakan dengan proses berpikir kritis. Pembelajaran IPA tingkat sekolah dasar mempelajari susunan peristiwa, fakta, konsep yang berhubungan dengan alam. Pembelajaran IPA membekali siswa berbagai disiplin ilmu dan mengembangkan daya pikir (Pamungkas, G. H., Harjono, N., \& Airlanda, G. S., 2019). Apabila pembelajaran IPA yang dilakukan secara ceramah, sedikitnya ruang interkasi berpikir tingkat tinggi dan pemberian soal-soal hanya membawa seseorang mencapai batasan aspek kognitif padahal masih ada aspek yang juga harus dicapai dan mampu membuka kepekaan pada diri secara cermat, menyaring, mengaplikasikan, serta turut memberi kontribusi bagi perkembangan science dan teknologi itu sendiri (Subiantoro, 2010). Pembelajaran yang ideal tidak hanya terfokus pada nilai atau hasil kerja siswa tetapi bagaimana siswa berproses sehingga menemukan titik temu atau jawaban atas permasalahan yang dihadapi. Pembelajaran IPA sendiri merupakan pembelajaran yang berkaitan dengan kehidupan dan lingkungan sekitar siswa. Dengan kata lain pembelajaran IPA yang ideal yaitu pembelajaran yang secara langsung dapat dipelajari siswa guna mengembangkan keterampilan berpikir kritis sehingga siswa dapat menemukan jawaban melalui pengelaman belajar yang dilakukan.
Pemilihan model pembelajaran dalam proses belajar juga mempengaruhi keberhasilan pencapain tujuan. Penggunaan PJBL (Project Based Learning) atau model pembelajaran berbasis proyek menjadi salah satu pilihan untuk mempermudah pemahaman terhadap materi pelajaran yang sedang dibahas karena memberikan praktek secara langsung bukan hanya abstrak sehingga apabila menemukan masalah dalam pembelajaran siswa mampu menganalisis masalah, memberikan tanggapan kritis terhadap masalah, dan menemukan solusi serta memudahkan guru dalam memberikan pengalaman belajar kepada siswa. Model pembelajaran PJBL sendiri pertama kali dikembangkan oleh John Dewey. PJBL merupakan sebuah pembelajaran yang melibatkan semua siswa dalam kegiatan pembelajaran serta memberi waktu lebih untuk siswa menyelesaikan masalah secara individu maupun kelompok (Natty, R. A., Kristin. f., Anugraheni, I., 2019). Penerapan model pembelajaran PJBL dalam pembelajaran IPA juga menjadi fasilitator bagi siswa dengan segala latar belakang kemampuan yang dimilikinya. Siswa akan menyampaikann pendapat mereka sesuai dengan apa yang mereka temukan sehingga menimbulkan diskusi yang menarik apabila terjadi perbedaan cara pemecahan masalah. Pendapat yang dikemukakan oleh (Hilkka Korpi, Liisa Peltokallio, Arja Piirainen , 2013), model pembelajaran PJBL mengaktifkan suatu proses yang memungkinkan siswa untuk berpartisipasi dan menemukan pengalaman yang berbeda dari sebelumnya sehingga siswa mampu merefleksikan pendapat secara kritis. Siswa selalu bertanya ketika menemukan suatu masalah atau memberikan pendapat yang sesuai dengan materi yang dijelaskan, contohnya apabila guru sedang menjelaskan mengenai sistem pencernaan maka siswa akan memberikan beberapa pertanyaan singkat hingga detail kepada guru. Dalam 
penerapannya akan timbul kegiatan belajar mengajar dua arah secara aktif.

Pembelajaran yang aktif dapat dinilai dari suasana kelas yang tetap kondusif dan sesuai dengan arah materi yang sedang dibahas serta bagaimana siswa mengikuti proses pembelajaran. Aktif bukan berarti hanya berani mengemukakan pendapat akan tetapi siswa memiliki dasar atas pendapat atau pertanyaan yang disampaikan yang biasa disebut sebagai keterampilan berfikir kritis. Diperkuat dengan pendapat (Azizah, M. Sulianto, J. Cintang, N, 2018), Keterampilan berpikir kritis merupakan suatu proses kognitif siswa dalam menganalisis masalah yang dihadapi secara sistematis dan spesifik, dapat membedakan masalah secara cermat dan teliti, serta mengidentifikasi dan mengkaji informasi untuk membuat strategi pemecahan masalah dalam pembelajaran.

Pembelajaran IPA identik dengan sumber daya alami maupun buatan sehingga pengembangkan model pembelajaran PJBL dapat memanfaatkan barang yang ada disekitar siswa sebagai bahan pembuatan proyek. Terdapat satu model yang juga sedang dikembangkan yang dapat melengkapi proses pembuatan proyek dengan bantuan science dan teknologi, model ini adalah STEM (Science, Technology, Engeineering, Mathematics). Setiap orang memiliki makna yang berbeda tentang penjelasan STEM semua bergantung pada bidang studi yang mereka ambil, kemungkinan pada bidang keilmuan berupa teknologi, teknik, matematika disesuaikan pada bidang masing-masing (White, 2014). STEM dan PJBL memiliki tujuan yang sama yaitu membantu siswa menyelesaikan masalah dengan sebuah hasil atau produk sehingga diharapkan siswa mampu mengembangkan keterampilan yang dimiliki, hanya saja berbeda dalam proses pelaksanaan dan pemilihan bahan. (Torlakson, 2014) menjelaskan,
"STEM mengajarkan dan melatih siswa untuk terlibat dalam pemikiran kritis, penyelidikan, pemecahan masalah, kolaborasi, dan rekayasa sebagai pemikiran desain." STEM memberikan dasar pemikiran secara sistematis terhadap materi atau permasalahan yang sedang dibahas. Penerapan STEM pertama kali dikembangkan di Amerika serikat dengan tujuan untuk pilihan karir utama bagi siswa (Permanasari, 2016). STEM merupakan kolaborasi yang serasi dari empat disiplin ilmu dalam suatu pembelajaran yang erat kaitan dengan penyelesaiaan masalah dikehidupan nyata. PJBL dan STEM saling melengkapi dengan kekurangan dan kelebihannya sehingga siswa mampu memahami konsep pembuatan produk yang dibantu oleh model pembelajran PJBL serta proses perancangan dan redesign (engineering design process) sehingga tercipta hasil produk yang sesuai (Lutfi, Ismail, Andi Asmawati Azis, 2018).

Penelitian yang dilakukan oleh (Arisanti,

2016) Analisis Penguasaan Konsep dan Keterampilan Berpikir Kreatif Siswa SD Melalui Project Based Learning pada pembelajaran IPA masing-masing kelas penelitian diberi pretest dan posttest dengan soal tes penguasan. Terdapat dua kelompok yaitu eksperimen menggunakan Project Based Learning dan kontrol menggunakan selain Project Based Learning kemudian konsep pengujian berupa 15 soal pilihan ganda dan 5 soal essay pada setiap tes untuk keterampilan berpikir kreatif. Terdapat perbedaan yang signifikan dalam penguasaan konsep antara kelompok eksperimen pada kategori sedang, dengan siswa yang belajar dengan menerapkan selain pembelajaran berbasis proyek dalam kategori rendah. Tidak ada perbedaan pada kemampuan berpikir kreatif antara kelas eksperimen dan kelas kontrol, dengan ratarata keduanya berada di kategori rendah. Dari penelitian ini penggunaan PJBL belum mampu 
347 Efektivitas Model Pembelajaran Project Based Learning Berbasis STEM dan Tidak Berbasis

STEM Terhadap Keterampilan Berpikir Kritis Siswa - Almahida Aureola Dywan, Gamaliel Septian Airlanda

mempengaruhi ketermapilan berpikir siswa memungkinan penggunaan STEM dapat melengkapi model pembelajaran yang digunakan.

Penelitian yang dilakukan oleh (Lestari, T. P., Sarwi. Sumarti, S. S., 2018) pada STEM-Based Project Based Learning Model to Increase Science Process and Creative Thinking Skills of 5th Grade mendapatkan hasil peningkatan yang signifikan pada keterampilan berpikir kreatif di kelas eksperimen 1. Peningkatan keterampilan berpikir kreatif dapat dikategori tinggi yaitu 23\% dan kategori menengah sebanyak 77\%. Pada kelas eksperimen 2, kategori tinggi pada presentase $4 \%$ dan dalam kategori sedang dengan presentase sebnayak 96\%. Dari penelitian ini disimpulkan model pembelajaran pembelajaran berbasis proyek STEM dapat meningkatkan keterampilan proses sains dan berpikir kreatif siswa. Dilihat dari hasil penelitian tersebut PJBL berbasis STEM telah mampu meningkatkan keterampilan berpikir siswa.

Melihat beberapa hasil penelitian menimbulkan ketertarikan penulis untuk menguji model pembelajaran dari kurikulum 2013 yaitu PJBL dengan atau tanpa STEM. Untuk mengetahui hasil dari penerapan STEM pada model pembelajaran PJBL terhadap keterampilan berpikir kritis siswa dalam pembelajaran IPA. Penyelesaian masalah pembelajaran IPA biasanya dilakukan dengan ekperimen atau pembuatan media pembelajaran sehingga cocok dengan penggunaan model pembelajaran PJBL. Hasil dari pengujian ini akan terlihat apakah model pembelajaran PJBL berbasis STEM atau PJBL tanpa STEM yang memiliki pengaruh lebih terhadap keterampilan berpikir kritis siswa pada pembelajaran IPA atau mungkin akan mengurangi keefektifan pembelajaran di dalam kelas.

\section{METODE}

Jenis penelitian yang akan digunakan adalah eksperimental. Penelitian eksperimental adalah suatu kontrol dan manipulasi kondisi terhadap penentu suatu peristiwa yang diminati, memperkenalkan intervensi dan mengukur perbedaan hasilnya (Cohen, L. Manion, L. Morrison, K. , 2007). Penelitian ini biasanya digunakan untuk membandingkan dua hal yang memiliki perbedaan hasil. Peneliti akan menggunakan Quasi Eksperimental Research atau eksperimental semu. Quasi Eksperimental Research tidak menggunakan tugas secara acak untuk siswa dalam kelompok (Creswell, 2012). Eksperimental semu adalah turunan dari eksperimental murni dimana lebih mudah untuk diterapkan karena tidak mengontrol semua variable tapi tetap mendekati penelitian yang sebenarnya.

Dalam penelitian ini ada dua kelompok yang akan diuji kelompok pertama merupakan kelompok yang hanya menggunakan model pembelajaran PJBL dan kelompok kedua adalah kelompok yang akan menggunakan PJBL berbasis STEM.

Desain penelitian yang akan digunakan adalah menggunakan desain Non-equivalen Control Group Desain. Dalam desain ini membandingkan dua kelompok, yaitu kelompok eksperimen dan kelompok kontrol. Ada dua kegiatan yang dilakukan untuk mengetahui keberhasilan penerapan model pembelajaran yaitu pre-test dan post-test. Pre-test memberikan ukuran pada beberapa atribut atau karakteristik utnuk peserta sebelum merek mendapat treatment (Creswell, 2012). Hal ini berarti dilakukan pre-test untuk mengetahui keadaan awal kemampuan berpikir kritis siswa terhadap suatu permasalahan menggunakan model pembelajaran PJBL berbasis STEM maupun tanpa STEM. Hasil dari uji eksperimen ini dikatakan baik apabila terjadi berubahan yang terjadi signifikan terhadap 
keterampilan berpikir kritis siswa dari kelompok eksperimen. Kemudian dilakukan post-test yang merupakan ukuran dari beberapa atribut atau karakteristik yang dinilai pada siswa setelah treatment (Creswell, 2012). Maka setelah post-test atau penilaian hasil ini berguna untuk mengetahui model pembelajaran mana yang lebih efektif terhadap pola berpikir kritis siswa dalam muatan pelajaran IPA.

\section{Tabel 1 Non-equivalent Control Group Design}

\begin{tabular}{|c|c|c|c|}
\hline Kelompok & $\begin{array}{c}\text { Pre- } \\
\text { test }\end{array}$ & $\begin{array}{c}\text { Variabel } \\
\text { Bebas }\end{array}$ & $\begin{array}{c}\text { Post- } \\
\text { test }\end{array}$ \\
\hline Eksperimen 1 & $\mathrm{O}_{1}$ & $\mathrm{X}_{1}$ & $\mathrm{O}_{2}$ \\
\hline Eksperimen 2 & $\mathrm{O}_{3}$ & $\mathrm{X}_{2}$ & $\mathrm{O}_{4}$ \\
\hline
\end{tabular}

Keterangan dari tabel 1:

$\mathrm{X}_{1}$ : Perlakuan eksperimen 1 (kelompok eksperimen) yaitu model pembelajaran PJBL berbasis STEM.

$\mathrm{X}_{2}$ : Perlakuan eksperimen 2 (kelompok kontrol) model Pembelajaran PJBL.

$\mathrm{O}_{1}$ : Hasil pretest untuk kelompok eksperimen.

$\mathrm{O}_{2}$ : Hasil posttest untuk kelompok eksperimen setelah setelah mengikuti pembelajaran PJBL berbasis STEM.

$\mathrm{O}_{3}$ : Hasil pretest untuk kelompok kontrol.

$\mathrm{O}_{4}$ : Hasil posttest untuk kelompok kontrol setelah mengikuti pembelajaran PJBL.

Dalam penelitian perlu ditentukan populasi dan sampel terlebih dahulu. Populasi merupakan kelompok besar dalam studi kuantitatif, dapat memungkinkan peneliti untuk membuat kesimpulan tentang kinerja kelompok (Gay, L. R. Mills, G. E. Airasian, P., 2012). Populasi dari penelitian ini diambil dari Gugus Gajah Mada kecamatan Sidomukti kota Salatiga. Sampel adalah sekelompok individu, item, atau peristiwa yang mewakili karakteristik kelompok yang lebih besar dari mana sampel diambil (Gay, L. R. Mills, G. E. Airasian, P., 2012). Sampel sekolah yang dituju SD Negeri Dukuh 01 Salatiga sebagai kelompok eksperimen dengan jumlah siswa 32 dan SD Negeri Kecandran 01 Salatiga sebagai kelompok kontrol dengan jumlah siswa 33.
Dalam penelitian ini terdapat 2 varibel yang digunakan, yaitu variebel bebas yang berupa model pembelajaran PJBL berbasis STEM dan PJBL serta variabel terikat yang berupa keterampilan berpikir kritis.

Teknik pengumpulan data merupakan cara yang digunakan leh peneliti untuk memperoleh data dari penelitian yang dilakukan. Data yang diperoleh dari penelitian ini berupa data hasil perkembangan pola pikir siswa. Untuk mengumpulkan data kemampuan berpikir kritis siswa akan dilakukan secara tes. Tes yang akan dilaksanakan untuk mengetahui keefekifan penggunaan model pembelajaran PJBL berbasis STEM dan PJBL akan dilaksanakan secara tertulis dalam bentuk uraian. Instrumen pengumpulan data yang akan digunakan dalam penelitian berupa lembar soal pre-test dan post-test dalam bentuk uraian. Penilaian untuk setiap soal urain dibagi menggunakan penskoran 1-5 penjabaran dari bentuk kualitatif skor yang dijadikan dalam kuantitatif skor. Instrument penilaian diawali dengan melakukan uji tingkat kesukaran untuk mngetahui standar kesukaran soal sebelum dinyata valid dan reliabel. Menurut (Asrul, A., Ananda, R., \& Rosnita, R., 2015) Adapun rumus mencari P adalah:

$\mathrm{P}=\frac{\mathrm{B}}{\mathrm{JS}}$

Keterangan:

$\mathrm{P}=$ Indeks kesukaran

$\mathrm{B}=$ Banyak siswa yang menjawab benar

$\mathrm{JS}=$ Jumlah seluruh siswa peserta tes

Dengan klasifikasi Soal dengan indeks kesukaran 0,00 sampai 0,30 merupakan soal sukar, indeks kesukaran 0,30 sampai 0,70 adalah soal sedang, dan indeks kesukaran 0,70 sampai 1,00 adalah soal mudah. Uji validasi soal dilaksanakan di SD Negeri 2 Deras kecamatan Kedungjati dimana dari 15 butir soal didapatkan soal valid sebanyak 10 soal. Pengujian validasi soal dilakukan 
349 Efektivitas Model Pembelajaran Project Based Learning Berbasis STEM dan Tidak Berbasis

STEM Terhadap Keterampilan Berpikir Kritis Siswa - Almahida Aureola Dywan, Gamaliel Septian Airlanda

menggunakan SPSS 20 for windows dengan ketentuan apabila pearson correlation lebih besar dari $\mathrm{R}_{\text {tabel }}$ maka soal dikatakan valid. Data kemudian diuji dengan pengujian reliabilitas dengan hasil 0,809 yang temasuk dalam data yang reliable.

Teknis analisis data yang digunakan yaitu analisi deskriptif dan analisis inferential. Analisis diskriptif merupakan salah satu analisis data yang telah dikumpulkan guna menggambarkan data dari suatu variable. Analisi deskriptif akan mengguanakan pengukuran mean, standar deviasi, nilai minimal, dan maksimal. Pengolahan data analisis deskriptif menggunakan SPSS 20 for windows. Analisis data deskriptif bertujuan untuk mengetahui berbedaan hasil sebelum diberikan treatment (pre-test) dan juga setelah diberikan treatment (post-test). analisis inferensial, sebagai uji persyaratan terdapat uji normalitas dan uji homogenitas. Untuk mengetahui hasil akhirnya dilakukan perhitungan uji beda atau uji $\mathrm{T}$ dengan bantuan SPSS 20 for windows menggunakan independent sample test.

\section{HASIL DAN PEMBAHASAN}

Dalam pembahasan hasil penelitian akan menunjukan data hasil belajar kelompok eksperimen dan kelompok kontrol berupa distribusi frekuensi sebelum dan setelah dilakukannya treatment. Perolehan data dari hasil pre-test dan post-test muatan pembelajaran IPA pada kelompok eksperimen yang diberlakukan model pembelajaran PJBL berbasis STEM. Data hasil interval nilai, frekuensi, dan presentase:

Tabel 2 Distribusi Frekuensi Pre-Test Kelompok Eksperimen

\begin{tabular}{|c|c|c|c|}
\hline No. & Interval & Frekuensi & Presentase \\
\hline 1. & $<60$ & 27 & $84,375 \%$ \\
\hline 2. & $61-70$ & 3 & $9,375 \%$ \\
\hline 3. & $71-80$ & 1 & $3,125 \%$ \\
\hline 4. & $81-90$ & 1 & $3,125 \%$ \\
\hline
\end{tabular}

\begin{tabular}{|c|c|c|}
\hline Jumlah & 32 & $100 \%$ \\
\hline
\end{tabular}

Sumber: data primer

Modus dari table tersebut terdapat pada interval < 60 dengan frekuensi 27 yang menjelaskan bahwa tingkat berpikir kritis masih sangat rendah. Interval tertinggi 81-90 atau nilai tertinggi hanya memiliki frekuensi sebanyak 1 sehingga dipresentasikan menjadi 3,125\%.

Tabel 3 Distribusi Frekuensi Post-Test Kelompok Eksperimen

\begin{tabular}{|c|c|c|c|}
\hline No. & Interval & Frekuensi & Presentase \\
\hline 1. & $0<60$ & 10 & $31,25 \%$ \\
\hline 2. & $61-70$ & 14 & $43,75 \%$ \\
\hline 3. & $71-80$ & 6 & $18,75 \%$ \\
\hline 4. & $81-90$ & 2 & $6,25 \%$ \\
\hline \multicolumn{2}{|c|}{ Jumlah } & 32 & $100 \%$ \\
\hline
\end{tabular}

Sumber: data primer

Dari post-test terdapat peningkatan nilai terlihat penurunan frekuensi pada interval $0<60$. Modus terletak pada interval 61 - 70 dengan frekuensi 14 serta nilai tertinggi berada di interval 81 - 90 dengan presentase meningkat menjadi $6,25 \%$.

Perolehan data dari hasil pre-test dan posttest muatan pembelajaran IPA pada kelompok eksperimen yang diberlakukan model pembelajaran. Data hasil berupa rata-rata, nilai maksimal, dan nilai minimal sebagai berikut:

Tabel 4 Distribusi Frekuensi Pre-Test Kelompok Kotrol

\begin{tabular}{|c|c|c|c|}
\hline No. & Interval & Frekuensi & Presentase \\
\hline 1. & $0<60$ & 24 & $72,73 \%$ \\
\hline 2. & $61-70$ & 9 & $27,27 \%$ \\
\hline \multicolumn{2}{|r|}{ Jumlah } & 33 & $100 \%$ \\
\hline
\end{tabular}

Sumber: data primer

Dari tabel diatas diketahui interval terendah $0<60$ yang memiliki frekuensi sangat tinggi yaitu 24 siswa dengan presentase 72,73. Pencapain nilai tertinggi berada pada interval 6170 memiliki presentase terkecil yaitu $27,27 \%$ yang berarti tingkat berpikir kritis juga masih terbilang rendah. 
350 Efektivitas Model Pembelajaran Project Based Learning Berbasis STEM dan Tidak Berbasis

STEM Terhadap Keterampilan Berpikir Kritis Siswa - Almahida Aureola Dywan, Gamaliel Septian

Airlanda

Tabel 5 Distribusi Frekuensi Post-Test Kelompok Kontrol

\begin{tabular}{|c|c|c|c|}
\hline No. & Interval & Frekuensi & Presentase \\
\hline 1. & $0<60$ & 15 & $45,45 \%$ \\
\hline 2. & $61-70$ & 15 & $45,45 \%$ \\
\hline 3. & $71-80$ & 3 & $9,10 \%$ \\
\hline \multicolumn{2}{|c|}{ Jumlah } & 33 & $100 \%$ \\
\hline
\end{tabular}

Sumber: data primer

Dari tabel diatas diketahui penurunan frekuensi pada interval $0<60$ yang sebelumnya 24 menjadi 15 yang menandakan terdapat peningkatan keterampilan berpikir kritis sehingga presentase turun menjadi 45,45\%. Frekuensi untuk interval 61 - 70 meingkat dari sebelumnya berada pada presentase $27,27 \%$ menjadi $45,45 \%$ yang berarti meningkat sebesar $18,18 \%$. Nilai tertinggi terdapat pada interval 71-80 yang dengan frekuensi 3 siswa, hal ini memperkuat bukti bahwa keterampilan berpikir kritis siswa meningkat.

Deskripsi komparasi membahas tentang perbandingan hasil data kemampuan berpikir kritis sebelum (pre-test) dan setelah (post-test) dilakukannya treatment antara kelompok eksperimen dan kelompok control. Berikut merupakan tabel dan diagram komparasi data hasil pengukuran kemampuan berpikir kritis siswa.

Tabel 6 Komparasi Data Hasi Pengukuran Keterampilam Berpikir Kritis Siswa

\begin{tabular}{|c|c|c|c|}
\hline \multirow[b]{2}{*}{$\begin{array}{c}\text { Hasil } \\
\text { Pengukuran }\end{array}$} & \multicolumn{2}{|c|}{ Rat-rata Skor (mean) } & \multirow[b]{2}{*}{ Selisih } \\
\hline & $\begin{array}{c}\text { Kelompok } \\
\text { Eksperimen }\end{array}$ & $\begin{array}{c}\text { Kelompok } \\
\text { Kontrol }\end{array}$ & \\
\hline Pre-test & 52,75 & 54,55 & 1,8 \\
\hline Post-test & 66,13 & 62,06 & 4,07 \\
\hline
\end{tabular}

Sumber: data primer

Dari data tabel diatas menunjukan komparasi hasil pengukuran rata-rata terjadi peningkatan dari pre-test ke post-test pada kedua kelompok. Kelompok eksperimen mengalami peningkatan dari rata-rata 52,75 menjadi 66,13 yang berarti meningkat sebesar 13,38 pada rata-

rata kelas. Sedangkan kelompok kontrol mengalami peningatan rata-rat kelas sebesar 7,51 yang semula 54,55 menjadi 62,06. Berikut disajikan diagram batang komparasi hasil data pengukuran kelompok eksperimen dan kelompok kontrol:

\section{Data Hasil Pengukuran Keterampilan Berpikir Kritis} Siswa

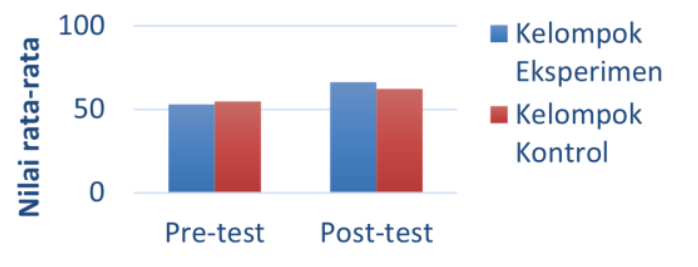

\section{Gambar 1. Data Hasil Pengukuran Keterampilan Berpikir Kritis}

Berdasarkan diagram diatas, dapat diketahui peningkatan nilai pada kelompok eksperimen dan kelompok kontrol. Selisih penigkatan keterampilan berpikir kritis dari kedua kelompok tersebut sebesar 5,87.

Analisis diskriptif merupakan salah satu analisis data yang telah dikumpulkan guna menggambarkan data dari suatu variable. Analisi deskriptif akan mengguanakan pengukuran mean, standar deviasi, nilai minimal, dan maksimal. Pengolahan data analisis deskriptif menggunakan SPSS 20 for windows. Analisis data deskriptif bertujuan untuk mengetahui berbedaan hasil sebelum diberikan treatment (pre-test) dan juga setelah diberikan treatment (post-test). Analisis data hasil dari pre-test dan post-test pada masingmasing kelompok akan disajikan dalam table skor hasil belajar. Maka disajikan table data hasil belajar kelompok eksperimen dan kelompok kontrol sebagai berikut: 
Table 7 Data Hasil Belajar Kelompok Eksperimen Descriptive Statistics

\begin{tabular}{|c|c|c|c|c|c|}
\hline & N & $\begin{array}{c}\text { Mini } \\
\mathrm{mu} \\
\mathrm{m}\end{array}$ & $\begin{array}{c}\text { Max } \\
\mathrm{imu} \\
\mathrm{m}\end{array}$ & $\begin{array}{c}\text { Mea } \\
\mathrm{n}\end{array}$ & $\begin{array}{c}\text { Std. } \\
\text { Deviati } \\
\text { on }\end{array}$ \\
\hline Pretest & 32 & 32 & 82 & $\begin{array}{c}52.7 \\
5\end{array}$ & 9.977 \\
Posttest & 32 & 54 & 84 & $\begin{array}{c}66.1 \\
3\end{array}$ & 7.482 \\
$\begin{array}{c}\text { Valid N } \\
\text { (listwise) }\end{array}$ & 32 & & & & \\
\hline
\end{tabular}

Berdasarkan tabel data diatas diketahui nilai mean atau rata-rata sebelum dilakukan treatment model pembelajaran PJBL berbasis STEM adalah 52,75 dengan standar deviasi 9,977 dan nilai terendah 32 serta nilai tertinggi 82 . Setelah diberikan treatment nilai rata-rata kelas adalah 66,13 dengan standar deviasi 7,482 memiliki nilai terendah 54 serta nilai tertinggi 84 . Pengolahan data hasil belajar siswa digunakan untuk membuat tabel distribusi frekuensi sebagai berikut:

Tabel 8 Data Hasil Belaiar Kelompok Kontrol Descriptive Statistics

\begin{tabular}{|l|c|c|c|c|c|}
\hline & N & $\begin{array}{c}\text { Mini } \\
\text { mum }\end{array}$ & $\begin{array}{c}\text { Maxi } \\
\text { mum }\end{array}$ & $\begin{array}{c}\text { Mea } \\
\mathrm{n}\end{array}$ & $\begin{array}{c}\text { Std. } \\
\text { Deviati } \\
\text { on }\end{array}$ \\
\hline Pretest & 33 & 30 & 70 & $\begin{array}{c}54.5 \\
5\end{array}$ & 9.569 \\
Posttest & 33 & 42 & 78 & $\begin{array}{c}62.0 \\
6\end{array}$ & 7.976 \\
$\begin{array}{l}\text { Valid N } \\
\text { (listwise) }\end{array}$ & 33 & & & & \\
\hline
\end{tabular}

Berdasarkan tabel data hasil belajar kelompok kontrol diketahui nilai mean atau ratarata sebelum dilakukan treatment model pembelajaran PJBL adalah 54,55 dengan standar deviasi 9,569 dan nilai terendah 30 serta nilai tertinggi 70. Setelah diberikan treatment nilai ratarata kelas adalah 62,06 dengan standar deviasi 7,976 memiliki nilai terendah 42 serta nilai tertinggi 78 .
Analisi data dilakukan dengan analisis inferensial, sebagai uji persyaratan terdapat uji normalitas dan uji homogenitas. Untuk mengetahui hasil akhirnya dilakukan perhitungan uji beda atau uji $\mathrm{T}$ dengan bantuan SPSS 20 for windows menggunakan independent sample test.

Uji normalitas merupakan kegiatan pengujian guna mengetahui apakah populasi mempunyai distribusi data yang normal atau tidak. Data dapat dikatakan berdistribusi normal apabila nilai signifikansi $>0,05$ sedangkan signifikansi $<0,05$ maka data tersebut berdistribusi dikatakan tidak normal. Data distribusi yang normal dapat menggunakan statistika parametrik, sedangkan data distribusi tidak normal akan digunakan statistik nonparametrik. Hasil data uji normalitas dari data pre-test dan post-test sebagai berikut:

Tabel 9 Hasil Data Normalitas Pre-Test

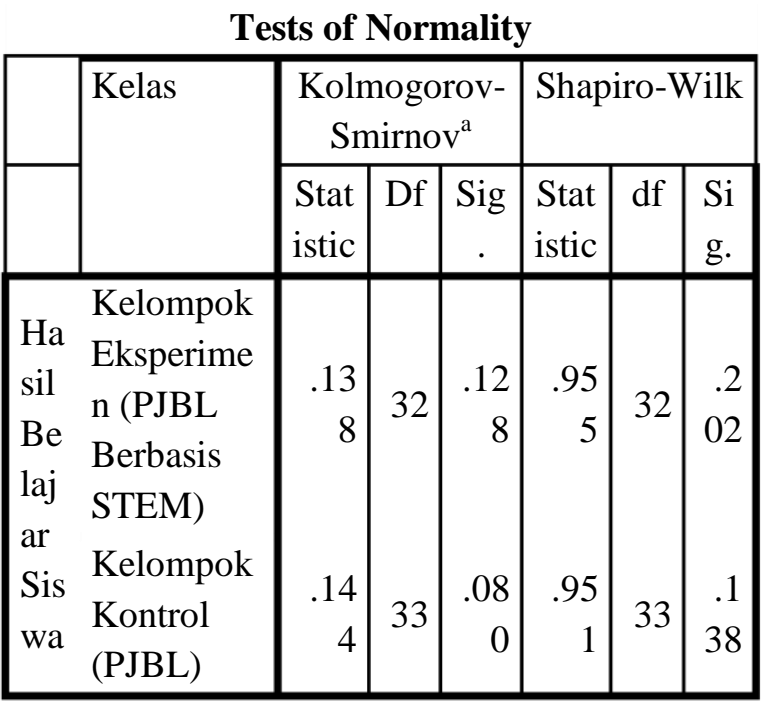

a. Lilliefors Significance Correction

Berdasarkan tabel diatas sesuai dengan standar nilai signifikansi nilai $0,128>0,05$ untuk kelompok eksperimen dan 0,08>0,05 maka data yang diuji dapat dikatakan normal. 
Table 10 Hasil Data Normalitas Post-test

\begin{tabular}{|c|c|c|c|c|c|c|c|}
\hline \multicolumn{8}{|c|}{ Tests of Normality } \\
\hline & \multirow[t]{2}{*}{ Kelas } & \multicolumn{3}{|c|}{$\begin{array}{c}\text { Kolmogorov } \\
\text {-Smirnov }\end{array}$} & \multicolumn{3}{|c|}{ Shapiro-Wilk } \\
\hline & & $\begin{array}{l}\text { Stat } \\
\text { istic }\end{array}$ & df & Sig & $\begin{array}{l}\text { Stat } \\
\text { istic }\end{array}$ & $\mathrm{df}$ & Sig \\
\hline $\begin{array}{l}\text { Hasil } \\
\text { Belajar } \\
\text { Siswa }\end{array}$ & $\begin{array}{l}\text { Kelompok } \\
\text { Eksperime } \\
\text { n (PJBL } \\
\text { Berbasis } \\
\text { STEM) } \\
\text { Kelompok } \\
\text { Kontrol } \\
\text { (PJBL) }\end{array}$ & $\begin{array}{r}.12 \\
4\end{array}$ & $\begin{array}{l}3 \\
3\end{array}$ & $\begin{array}{r}.20 \\
0^{*}\end{array}$ & .973 & $\begin{array}{l}3 \\
3\end{array}$ & $\begin{array}{r}.57 \\
0\end{array}$ \\
\hline
\end{tabular}

*. This is a lower bound of the true significance.

a. Lilliefors Significance Correction

Berdasarkan tabel diatas sesuai dengan standar nilai signifikansi nilai 0,094>0,05 untuk kelompok eksperimen dan 0,973>0,05 maka data yang diuji dapat dikatakan normal.

Uji homogenitas dilakukan guna mengetahui variasi yang berasal dari populasi. Apabila nilai signifikansi menunjukkan >0,05 berarti data dapat dinyatakan homogen, sebaliknya nilai signifikansi $<0,05$ dapat dinyatakan bahwa data tidak homogen. Hasil data homogenitas diperoleh dari data pre-test dalam tabel berikut:

Tabel 11 Hasil Data Homogenitas Pre-Test Test of Homogeneity of Variances

Hasil Belajar Siswa

\begin{tabular}{|r|r|r|l|}
\hline $\begin{array}{c}\text { Levene } \\
\text { Statistic }\end{array}$ & \multicolumn{1}{|c|}{ df1 } & \multicolumn{1}{c|}{ df2 } & \multicolumn{1}{c|}{ Sig. } \\
\hline .036 & 1 & 63 & .849 \\
\hline
\end{tabular}

Nilai signifikansi menunjukkan >0,05 berarti data dapat dinyatakan homogen, sebaliknya nilai signifikansi $<0,05$ dapat dinyatakan bahwa data tidak homogeny. Nilai signifikansi dari pretest adalah 0.902 maka hasil data dinyatakan homogen.
Tabel 12 Hasil Data Homogenitas Post-Test

Test of Homogeneity of Variances

Hasil Belajar Siswa

\begin{tabular}{|r|r|r|r|}
\hline $\begin{array}{c}\text { Levene } \\
\text { Statistic }\end{array}$ & \multicolumn{1}{|c|}{ df1 } & \multicolumn{1}{c|}{ df2 } & \multicolumn{1}{c|}{ Sig. } \\
\hline .015 & 1 & 63 & .902 \\
\hline
\end{tabular}

Nilai signifikansi menunjukkan $>0,05$ berarti data dapat dinyatakan homogen, sebaliknya nilai signifikansi $<0,05$ dapat dinyatakan bahwa data tidak homogeny. Nilai signifikansi dari pretest adalah 0.902 maka hasil data dinyatakan homogen.

Tabel 13 Distribusi Hasil Uji T

Independent Sample T Test

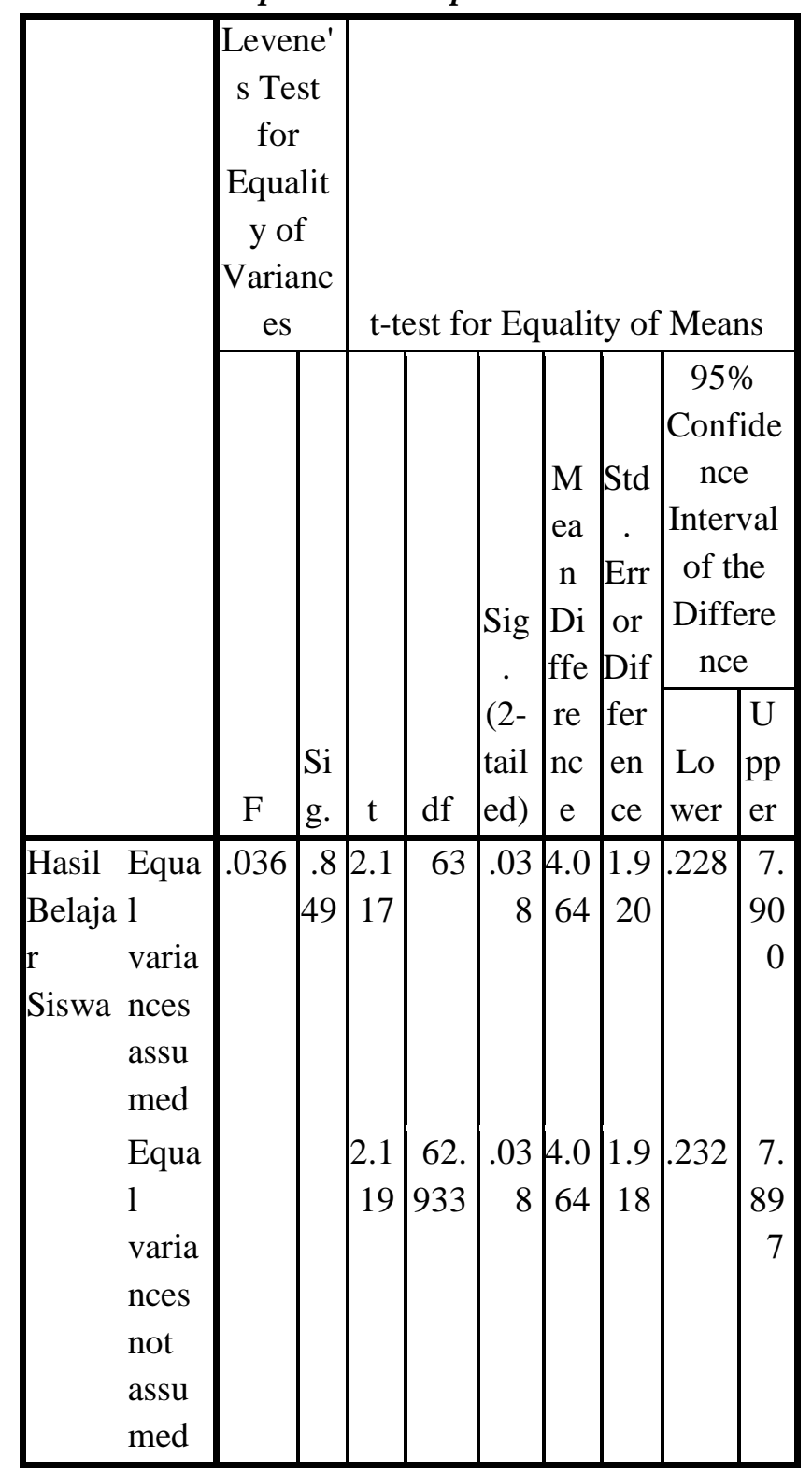


353 Efektivitas Model Pembelajaran Project Based Learning Berbasis STEM dan Tidak Berbasis

STEM Terhadap Keterampilan Berpikir Kritis Siswa - Almahida Aureola Dywan, Gamaliel Septian Airlanda

Berdasarkan data tabel 4.5, hasil uji $\mathrm{T}$ menggunakan independent sample $T$ test menunjukkan bahwa $t_{\text {hitung }} 2,117$ dengan signifikansi kolom sig(2-tailed) sebesar 0,038. Perbedaan rata-rata dari kelompok mean difference sebesar 4,064 .

Uji hipotesis adalah sebuah uji yang digunakan untuk mengetahui perbedaan hasil yang ada dalam kelas eksperimen dan kelas kontrol dari yang sebeumnya hanya praduga. Dalam penelitian ini terdapat dua hipotesis yaitu hipotesis awal $\left(\mathrm{H}_{0}\right)$ yang merupakan dugaan sementara dari peneliti dan hipotesis akhir $\left(\mathrm{H}_{1}\right)$ merupakan hasil dari penelitian yang telah dilakukan. Melalui uji $\mathrm{T}$ dapat diketahui perbedaan rata-rata dari sampel dua kelompok yang berbeda yaitu kelompok eksperimen dan kelompok kontrol. Perhitungan uji Tdengan bantuan SPSS 20 for windows akan diperoleh besar signifikansi dari hasil keterampilan berpikir kritis siswa. Berdasarkan hasil kriteria pengujian hipotesis, bahwa nilai signifikasi menunjukkan $0,038<0,05$ sehingga $\mathrm{H}_{0}$ ditolak dan $\mathrm{H}_{1}$ diterima. Maka dari hasil uji hipotesis dapat disimpulkan terdapat adanya perbedaan efektivitas model pembelajaran PJBL berbasi STEM dan tidak berbasis STEM terhadap keterampilan berpikir kritis siswa kelas IV. Model pembelajaran PJBL berbasis STEM dan tidak berbasis STEM dapat meningkatakan keterampilan berpikir kritis siswa. Keberhasilan penelitian dibutikan dengan meningkatnya rata-rata hasil pre-test dan post-test sehingga terdapat berbedaan yang signifikan setalah dilakukannya treatment menggunakan kedua model tersebut. Dengan analisis data yang telah dilakukan menunjukkan hasil menggunakan model pembelajaran PJBL berbasis STEM lebih tinggi dalam meningkatan keterampilan berpikir kritis siswa disbanding PJBL tidak berbasis STEM.

\section{SIMPULAN}

Berdasarkan data penelitian yang dilakukan dan pembahasan yang telah dipaparkan, maka dapat disimpulkan bahwa terdapat pengaruh pada keterampilan berpikir kritis siswa kelas IV SD Negeri Dukuh 01 Salatiga dan SD Negeri Kecandran 01 Salatiga dari kedua model pembelajaran yang digunakan yaitu model pembelajaran PJBL (Project based learning) berbasis STEM (Secience, Technology, Engineering, Mathemathic) serta penggunaan PJBL tanpa STEM. Hal tersebut didukung dari hasil uji t, dapat dilihat signifikansi dari keefektifan penggunaan model pembelajaran menunjukkan $0,38<0,05$ yang artinya terdapat pengaruh yang signifikan. Peningkatan kemampuan berpikir kritis juga dapat diukur dari peningkatan nilai pre-test ke post-test. Rata-rata nilai kelompok eksperimen meningkat sebesar 13,38 sedangkan pada kelompok kontrol meningkat sebesar 7,51 maka dari data tersebut penggunaan model pembelajaran PJBL berbasis STEM lebih efektif dalam meningkatkan keterampilan berpikir kritis siswa kelas IV muatan pembelajaran IPA.

Selain model pembelajaran yang digunakan ada beberapa hal yang juga mempengaruhi keterampilan berpikir kritis siswa di dalam kelas. Skills individu atau kemampuan setiap siswa menjadi faktor penting dalam pengaruh peningkatan keterampilan berpikir kritis, menggunakan model pembelajaran apapun apabila siswa memiliki kemampuan yang lebih maka pembelajaran akan diterima dengan mudah serta untuk meningkatankan variabel terikat (variabel y) tidak membutuhkan effort yang terlalu besar. Kemudian pengaruh situasi ruang belajar seperti model tempat duduk yang digunakan. Dari hasil penelitian tempat duduk yang dibuat secara berkelompok memiliki pengaruh lebih baik dalam 
354 Efektivitas Model Pembelajaran Project Based Learning Berbasis STEM dan Tidak Berbasis STEM Terhadap Keterampilan Berpikir Kritis Siswa - Almahida Aureola Dywan, Gamaliel Septian Airlanda

meningkatkan keterampilan berpikir kritis dibanding tempat duduk berbanjar. Hal ini terjadi karena dengan tempat duduk yang berkelompok mendorong siswa untuk melakukan banyak diskusi sehingga siswa dapat menemukan informasi baru sesuai dengan jawaban yang dibutuhkan.

\section{DAFTAR PUSTAKA}

Arisanti, W. O. (2016). Analisis Penguasaan Konsep dan Keterampilan Berpikir Kreatif Siswa SD Melalui Project Based Learning . EduHumaniora| Jurnal Pendidikan Dasar Kampus Cibiru, 8(1), 82-95.

Asrul, A., Ananda, R., \& Rosnita, R. (2015). Evaluasi Pembelajaran.

Azizah, M. Sulianto, J. Cintang, N. (2018). Analisis Keterampilan Berpikir kritis Siswa Sekolah Dasar pada Pembelajaran Matematika Kurikulum 2013. Semarang: UNNES.

Cohen, L. Manion, L. Morrison, K. . (2007). Research Methods in Education. New York: the Taylor \& Francis e-Library.

Creswell, W. J. (2012). Educational Research: Planning, Conducting, and Evaluating Quantitative and Qualitative Research . Boston, United States of America: Pearson Education.

Gay, L. R. Mills, G. E. Airasian, P. (2012). Educational research : competencies for analysis . USA: Pearson Education.

Hilkka Korpi, Liisa Peltokallio, Arja Piirainen . (2013). Problem-Based Learning in Professional Studies from the Physiotherapy Students' Perspective. Interdisciplinary Journal of Problem Base Learning.

Lestari, T. P., Sarwi. Sumarti, S. S. (2018). STEMBased Project Based Learning Model to Increase Science Process and Creative Thinking Skills of 5th Grade . Journal of Primary Education. Universitas Negeri Semarang.

Lutfi, Ismail, Andi Asmawati Azis. (2018). Pengaruh Project Base Learning Terintegrasi Stem Terhadap Literasi Sains, Kreativitas dan Hasil Belajar Peserta Didik. Prosiding Seminar Nasional Biologi dan Pembelajarannya , 189-194.

Natty, R. A., Kristin. f., Anugraheni, I. (2019). Peningkatan Kreativitas dan Hasil Belajar
Siswa Melalui Model Pembelajaran Project Based Learning Pada Siswa Sekolah Dasar. JURNAL BASICEDU, 1082-1092.

Pamungkas, G. H., Harjono, N., \& Airlanda, G. S. (2019). Peningkatan Proses dan Hasil Belajar IPA Kelas 5 Tema 6 Subtema 3 dengan Model Pembelajaran Discovery Learning. Jurnal Basicedu, 3(1), 43-46.

Permanasari, A. (2016). STEM Education: Inovasi dalam Pembelajaran Sains. Surakarta: Prosiding Seminar Nasional Pendidikan Sains.

Subiantoro, A. W. (2010). Pentingnya Praktikum dalam Pembelajaran IPA. Yogyakarta: Universitas Negeri Yogyakarta.

Torlakson, T. (2014). Innovate: A Blueprint for Science, Technology, Engineering, and Mathematics in California Public Education. California: Californians Dedicated to Education Foundation.

White, D. W. (2014). What is STEM education and why is it important. Florida Association of Teacher Educators Journal, 1(14), 1-9. 